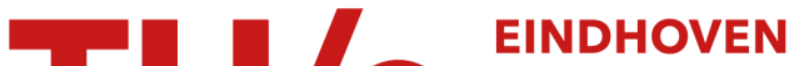 UNIVERSITY OF TECHNOLOGY
}

\section{Double-peak switching current in soft ferroelectric lead zirconate titanate}

Citation for published version (APA):

Kamel, T. M., \& With, de, G. (2007). Double-peak switching current in soft ferroelectric lead zirconate titanate. Journal of Applied Physics, 102(4), 044118-1/5. [044118]. https://doi.org/10.1063/1.2767188

DOI:

$10.1063 / 1.2767188$

Document status and date:

Published: 01/01/2007

\section{Document Version:}

Publisher's PDF, also known as Version of Record (includes final page, issue and volume numbers)

\section{Please check the document version of this publication:}

- A submitted manuscript is the version of the article upon submission and before peer-review. There can be important differences between the submitted version and the official published version of record. People interested in the research are advised to contact the author for the final version of the publication, or visit the $\mathrm{DOI}$ to the publisher's website.

- The final author version and the galley proof are versions of the publication after peer review.

- The final published version features the final layout of the paper including the volume, issue and page numbers.

Link to publication

\section{General rights}

Copyright and moral rights for the publications made accessible in the public portal are retained by the authors and/or other copyright owners and it is a condition of accessing publications that users recognise and abide by the legal requirements associated with these rights.

- Users may download and print one copy of any publication from the public portal for the purpose of private study or research.

- You may not further distribute the material or use it for any profit-making activity or commercial gain

- You may freely distribute the URL identifying the publication in the public portal.

If the publication is distributed under the terms of Article 25fa of the Dutch Copyright Act, indicated by the "Taverne" license above, please follow below link for the End User Agreement:

www.tue.nl/taverne

Take down policy

If you believe that this document breaches copyright please contact us at:

openaccess@tue.nl

providing details and we will investigate your claim. 


\title{
Double-peak switching current in soft ferroelectric lead zirconate titanate
}

\author{
Talal M. Kamel ${ }^{\text {a) }}$ and Gijsbertus de With ${ }^{\text {b) }}$ \\ Laboratory of Materials and Interface Chemistry, Eindhoven University of Technology, \\ $5600 \mathrm{MB}$ Eindhoven, The Netherlands
}

(Received 22 March 2007; accepted 17 June 2007; published online 30 August 2007)

\begin{abstract}
Switching current measurements have been carried out on a soft lead zirconate titanate (PXE52, donor doped, modified proprietary composition with the overall formula $\mathrm{PbZr}_{0.415} \mathrm{Ti}_{0.585} \mathrm{O}_{3}$ ). The experiments showed a single switching current peak during the application of electric field to a nonpoled (virgin) sample. However, an unusual double peak for the switching current was observed upon reversing the electric field polarity. The pyrocurrent for a forward and reverse poled sample showed a related behavior. A single pyropeak is observed in the forward poled case and broadened peak was observed in case of a reverse poled sample. This behavior is attributed to non- $180^{\circ}$ domain switching during the reverse poled case as a result of residual stresses developed during the forward poling. (C) 2007 American Institute of Physics. [DOI: 10.1063/1.2767188]
\end{abstract}

\section{INTRODUCTION}

The first quantitative experiments to determine the electric field and time dependence of domain reorientation were reported by $\mathrm{Merz}^{1}$ for $\mathrm{BaTiO}_{3}$ (BT) single crystals. In Merz's experiments, a sample was subjected to square pulse to align all dipoles in one direction followed by a second square pulse of opposite polarity. A single switching current peak as a function of time was obtained.

Recently we reported on the optimum poling conditions for a soft ferroelectric ceramic lead zirconate titanate (PZT). ${ }^{2}$ Our approach was to employ some preconditions of poling followed by evaluation of the degree of polarization by different methods. Pyrocurrent measurements were found to be a very useful tool to assess the polarization state. The measurements of the switching current enabled us to calculate the polarization, which was found to be consistent with the spontaneous polarization as calculated from the pyroelectric current. Thus, using both switching current and pyrocurrent, insight to the mechanism of polarization in soft ferroelectrics can be gained.

In an extension to our previous work ${ }^{2}$ on a soft PZT ceramic, following an approach similar to Merz's, we observed that the switching current showed two peaks as a function of time instead of the commonly observed single one. In the present article a possible explanation for the appearance of the double peaked switching current is introduced. The explanation is based on the phenomenon of a field-induced internal stresses. ${ }^{3-6}$

Merz ${ }^{1}$ and his co-worker ${ }^{7}$ proposed that the field applied antiparallel to the polarization direction switches the polarization from $-P$ to $+P$ showing a single switching current peak. The area under the curve equals

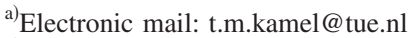

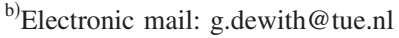

$$
\int_{0}^{t_{\mathrm{sW}}} J_{\mathrm{sw}} d t=2 P_{\mathrm{sw}}=\text { constant, }
$$

where $J_{\mathrm{sw}}$ and $t_{\mathrm{sw}}$ are the switching current density and switching time, respectively. The last step in Eq. (1) can be made since switching occurs at any field given enough time and the polarization is independent of the applied field and constant after sufficient switching time. Several authors studied field-induced phase transformations in ferroelectrics. Fan and $\mathrm{Kim}^{8}$ showed that when ferroelectric domains in a polycrystalline ceramic are subjected to a static electric field, the polar axes of (both the tetragonal and rhombohedral phases) tend to be aligned with the direction of the applied field. Using x-ray diffraction they showed that when the tetragonal and rhombohedral phases are coexisting together in the ferroelectric ceramic, upon applying an electric field the relative intensities of the rhombohedral reflections decreased after poling, while those of the tetragonal reflections increased. When the perovskite was mainly in the rhombohedral phase, the poling process increased the intensity of the rhombohedral peak, but there was no phase transformation to the tetragonal phase. Similarly, the phase transformation did not occur when the specimen was composed mainly of the tetragonal phase but in this case extensive $90^{\circ}$ domain switching occurred during the poling process. ${ }^{8}$

Liu et al. ${ }^{3}$ made in situ $\mathrm{x}$-ray diffraction experiments to observe non- $180^{\circ}$ domain switching and a phase transition at different electric fields for nonpoled and poled PZT specimens. They showed that, upon application of an electric field of $E_{C}$ to a nonpoled sample, the intensity of the tetragonal $T(002)$ peak increases while that of $T(200)$ decreases, indicating $90^{\circ}$ domain switching of the tetragonal phase from the (200) to the (002) orientation. Moreover, the intensity of the rhombohedral $R(200)$ peaks decreases upon applying an electric field, indicating a phase transition from rhombohedral to tetragonal, $R(200)$ to $T(002)$. In the case of a polarized sample, they found that upon application of an electric field of $+E_{C}, 90^{\circ}$ domain switching occurs, indicated by a 


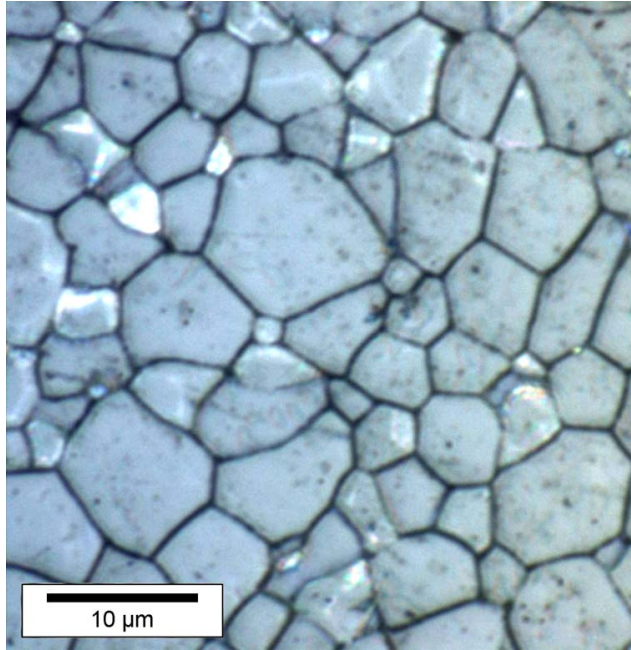

FIG. 1. Scanning electron microscopy micrograph of a nonpoled sample.

change from $T(200)$ to $T(002)$ and a phase transition, resulting in a change from $R(200)$ to $T(002)$, is induced but only to a very minor extent. While applying an electric field of $-0.8 E_{C}$ induces $90^{\circ}$ domain switching as indicated by a change from $T(002)$ to $T(200)$ and a phase transition resulting in a change from $T(002)$ to $R(200)$ is induced to a large extent. They attributed those field-induced phase transformations to the residual stresses developed during poling.

\section{EXPERIMENT}

Nonpoled polycrystalline ceramic samples of soft PZT (PXE52, donor doped, modified proprietary composition with the overall formula $\mathrm{PbZr}_{0.415} \mathrm{Ti}_{0.585} \mathrm{O}_{3}$ ) were obtained from Morgan Electro Ceramics BV, Eindhoven, The Netherlands. The dimensions of the samples under study were 5 $\times 5 \times 0.2 \mathrm{~mm}^{3}$. The microstructure of the samples was investigated after grinding, successive polishing, and etching.

The switching current measurements were carried out using a Keithley 6517 electrometer on initially nonpoled samples using a ramping electric field of $0.05 \mathrm{kV} / \mathrm{cm} \mathrm{s}$. The electric field was applied using the Keithley built-in voltage source with a response time of $5 \mathrm{~ms}$ at $0.1 \mathrm{kV}$ and $80 \mathrm{~ms}$ at $1 \mathrm{kV}$ and varied until a maximum field of $25 \mathrm{kV} / \mathrm{cm}$ was reached. The pyroelectric measurements were carried out using the direct method. ${ }^{9}$ Experimental details for the pyroelectricity experiments are described in detail in Ref. 2.

\section{RESULTS}

The microstructure of the nonpoled ceramic PZT used is shown in Fig. 1. The density was $7.45 \mathrm{~g} / \mathrm{cm}^{3}$ while the average grain size as measured using linear intercept method for 200 grains was $4.5 \mu \mathrm{m}$. Attempts to visualize the changed domain structure after switching failed due to the influence of the surface on the domain structure: the surface domain structure appeared to be largely fixated. It is well known that the domain structure in the bulk of the specimens may behave rather different from that near the surface. ${ }^{10}$ X-ray diffraction (XRD) patterns show the existence of several phases, the amount of which depends on the tempera-

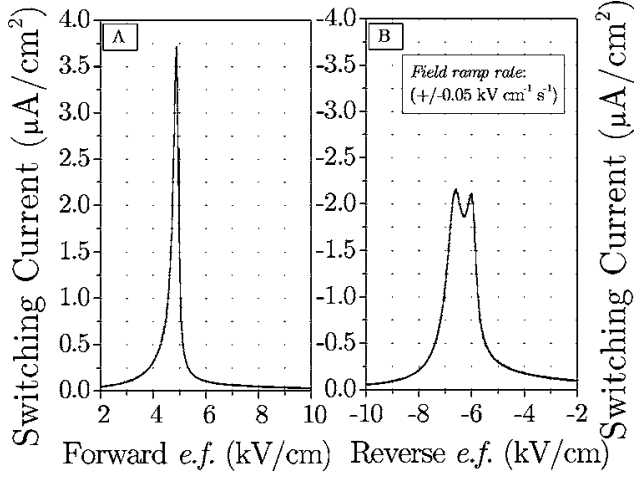

FIG. 2. (a) Switching current peak during positive poling. (b) Double switching current peak during subsequent negative poling.

ture, due to the modified composition. In view of this complexity, no further attempts were made to reveal the crystallographic nature of the specimens by XRD.

In Merz's experiments on BT single crystals, a sample is subjected to square pulse to align all dipoles in one direction followed by a second square pulse of opposite polarity and a single switching current peak as a function of time was obtained. ${ }^{1,7,11-16}$ In our experiments we followed a slightly different approach. An initially nonpoled sample is subjected to an electric field rate $\dot{E}_{f}$ of $5 \times 10^{-2} \mathrm{kV} / \mathrm{cm} \mathrm{s}$ in the forward direction, showing a single switching peak at 4.9 $\mathrm{kV} / \mathrm{cm}$ [Fig. 2(a)]. The corresponding polarization at the end of the process $(500 \mathrm{~s})$ is $45 \mu \mathrm{C} / \mathrm{cm}^{2}$. Upon applying the same field rate in the reverse direction $\dot{E}_{f}$, a double switching peak is observed at $E_{r 1}=6.0 \mathrm{kV} / \mathrm{cm}$ and $E_{r 2}=6.6 \mathrm{kV} / \mathrm{cm}$ [Fig. 2(b)]. The corresponding saturation polarization is $P_{\text {sat }}=85 \mu \mathrm{C} / \mathrm{cm}^{2}$ implying that Merz's thesis, Eq. (1), is satisfactorily verified (Fig. 3).

The double peak switching current was confirmed by recording the pyroelectric signal for forward and reverse poled samples. Figure 4(a) shows the pyroelectric coefficient after a forward poling. A single pyropeak is observed at the Curie transition temperature $\left(168^{\circ} \mathrm{C}\right)$. Figure $4(\mathrm{~b})$ shows the pyrosignal after reverse poling. Consistently with the switching curves a broad peak appeared at the Curie temperature, indicative of a combination of two peaks close to each other. Both the switching and the pyroelectric current double peak are continuously observed confirming of this behavior.

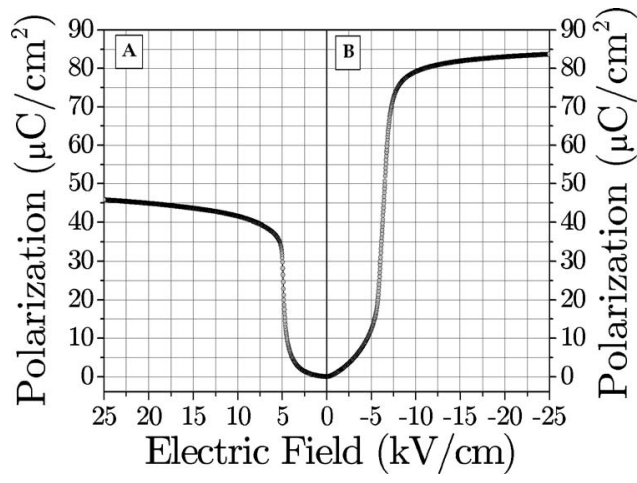

FIG. 3. Polarization as calculated from the pyrocurrent for forward and reverse field. 


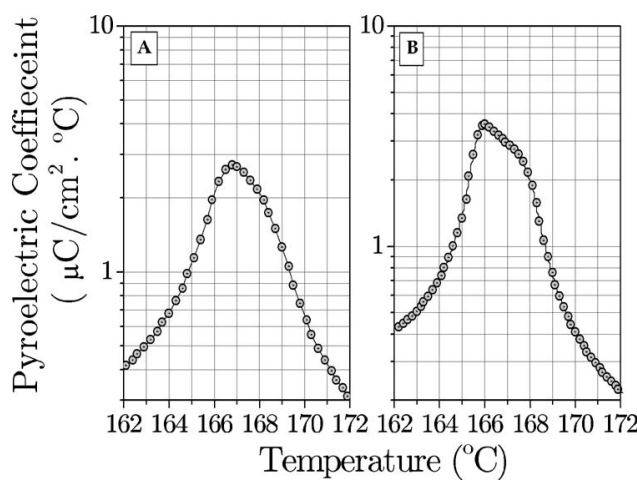

FIG. 4. Pyroelectric coefficient as a function of temperature for a forward (positive) and reverse (negative) poled sample.

Figure 5 shows a subsequent poling-switching process. In this process, a nonpoled sample is subjected to a ramping poling field reaching a maximum of $20.7 \mathrm{kV} / \mathrm{cm}$. In this process a single peak is observed. Upon reversing the field on the opposite direction a double peak is observed. Upon subsequent field reversal (forward and reverse) the double peak switching is permanently observed.

The development of the poling was studied by gradually increasing the maximum forward field. Figure 6 shows that, as long as during the poling process the ramping is stopped before major polarization takes place at approximately $5 \mathrm{kV} /$ $\mathrm{cm}$, only a single reverse switching peak is observed. Surprisingly the reverse peak for the very low maximum forward field of $2.3 \mathrm{kV} / \mathrm{cm}$ occurs at a field of about $4.8 \mathrm{kV} / \mathrm{cm}$, which is lower than the forward poling peak. A bias field could explain this effect. However, the samples at higher fields do not show this effect and for soft PZT a bias field is not expected. We thus have no explanation so far for this effect. With increasing maximum forward field, a double reverse peak develops as soon as the major forward polarization has taken place. The splitting of the reverse peak is illustrated in Fig. 7 and increases from initially 0.28 to about $0.61 \mathrm{kV} / \mathrm{cm}$, remaining largely constant for larger fields.

It has been shown ${ }^{17}$ for PZT-5 that a sudden poling instead of gradual poling results in a quite different behavior for switching. The effect is ascribed to the collective motion of all domain walls during a sudden pulse as compared with

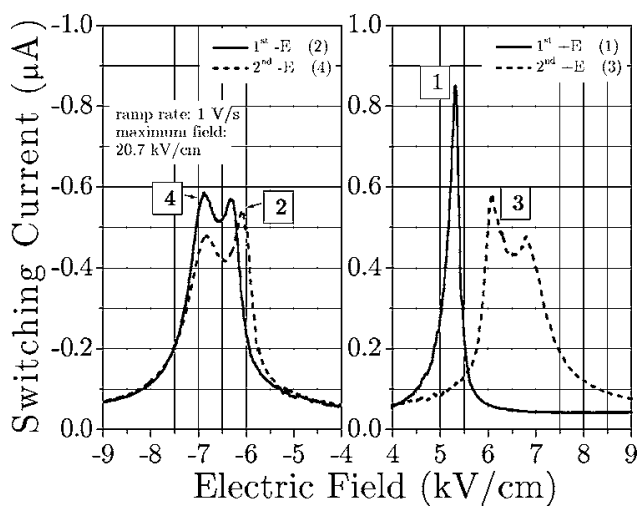

FIG. 5. Successive switching processes showing a single peak in the first poling for a virgin sample and permanently appearing double peak upon subsequent poling.

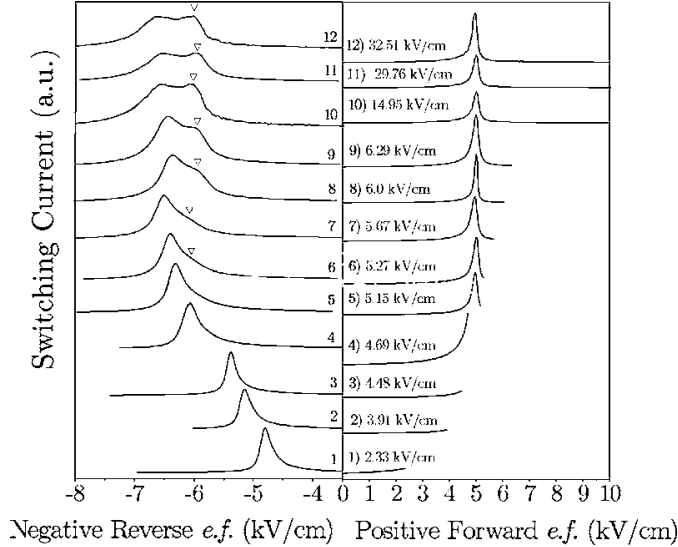

FIG. 6. Developing the double peak gradually with increasing the maximum forward field.

a more sequential change in domain structure for gradual poling. For our material a maximum field of $15 \mathrm{kV} / \mathrm{cm}$ was suddenly applied and the switching monitored. Peak splitting was again observed and found to be same as for the gradual poling, Fig. 8, although the ratio of the two peaks is different.

\section{DISCUSSION}

It is well known that during the phase transition of PZT, from the paraelectric (cubic) to the ferroelectric (tetragonal) phase, spontaneous polarization occurs. This tetragonal structure is in a stable (equilibrium) state, in which both $90^{\circ}$ and $180^{\circ}$ domain walls are formed to reduce the effects of the elastic energy and depolarizing electric fields, respectively. However, some residual stress will exist. Other stable (equilibrium) states exist and they can be realized by reversing the direction of polarization $\left(180^{\circ}\right.$ domain switching) and changing the polarization direction to the transverse directions $\left(90^{\circ}\right.$ domain switching). When an external force (mechanical stress or electric field) is applied, the ferroelectric material may move from one equilibrium state to another, due to domain switching. This switch depends on the magnitude and direction of the load. An electric field can cause

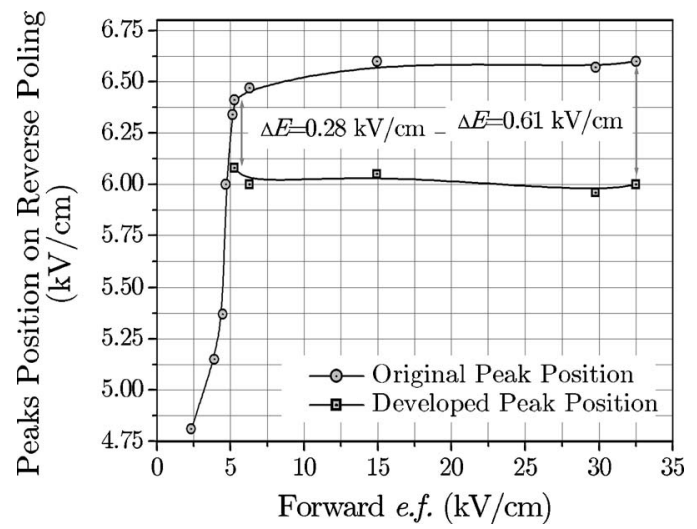

FIG. 7. Reversed double peak splitting $\Delta E$ as a function of the maximum forward field. 


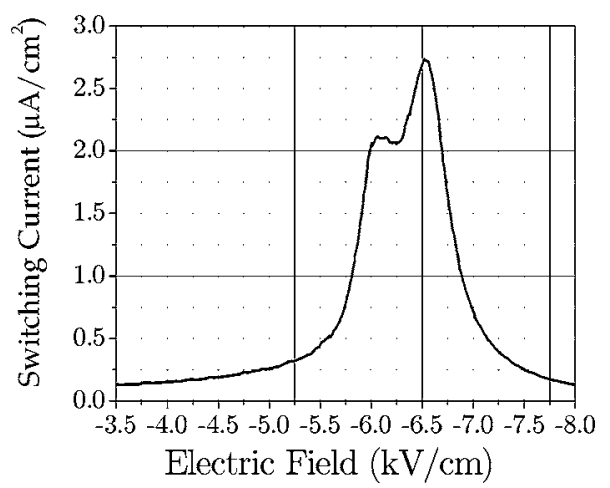

FIG. 8. Double peak switching after sudden forward poling with $15 \mathrm{kV} / \mathrm{cm}$.

both $180^{\circ}$ and $90^{\circ}$ domain switching, depending on the direction of the electric field, but a mechanical stress can only cause $90^{\circ}$ domain switching. ${ }^{5}$

Several criteria have been advanced to explain this domain switching. A brief review is given in Ref. 5. Two criteria are relevant at present. The first criterion, proposed by Liu et $a l^{3}$ and not reviewed in Ref. 5, suggests a threshold in electric field. These authors propose that in nonpoled samples residual stresses are low and uniformly distributed throughout the material. This assumption possibly leads to a threshold electric field for domain switching similar in all grains. Once such a threshold is reached, $180^{\circ}$ and non- $180^{\circ}$ domain switching may occur. However, in a polarized sample due to the complicated and inhomogeneous residual stress distribution ${ }^{18}$ the threshold for switching may differ significantly from grain to grain. ${ }^{3}$ Therefore, different types of domain wall switch at different applied electric field levels. The developing of internal stresses due to an electric field is an observation that dates from two decades ago. ${ }^{19,20}$

The second criterion, proposed by Sun and Achuthan and the one that showed the best agreement with experiment, is an internal-energy-density criterion. They assumed that, when an external electric field is applied in the direction of the spontaneous polarization, minor or no switching occurs. When an electric field is applied in a direction opposite to the polarization, switching to the $180^{\circ}$ equilibrium state is enabled. Thus only an electric field in the direction opposite to the direction of spontaneous polarization can produce $180^{\circ}$ domain switching. In the case of an electric field applied in the direction perpendicular to the spontaneous polarization, deformation is due to shear strain. Such a deformation can only result in $90^{\circ}$ domain switching. The internal-energydensity criterion as set by Sun and Achuthan ${ }^{5}$ is based on the assumption that the $180^{\circ}$ and $90^{\circ}$ domain switching are two independent modes of switching and that they take place when the respective internal-energy density reaches a critical value. It is assumed that the $180^{\circ}$ domain switching can only be realized by a reverse electric field and the internal-energy density due to this reverse electric field is considered to be the driving force for the $180^{\circ}$ domain switching. Similarly, the $90^{\circ}$ domain switching can only be produced by a compressive stress in the poling direction or an electric field perpendicular to the poling direction and the internal-energy density due to these two loads is considered the driving force for the $90^{\circ}$ domain switching. However, a reverse electric field enables $180^{\circ}$ domain switching and acts in the same time as a shear stress force for $90^{\circ}$ domain switching as long as the threshold energy for this switching is reached. ${ }^{3}$

If we assume that the difference between the two reverse peak positions is due to internal stress, an estimate for this stress can be made using the model as described in Ref. 5. Using the values for the field as observed in our experiments, we estimated the stress to be about $30 \mathrm{MPa}$. This value seems to be not unreasonable, in view of the limited amount of information on internal stress that is available. ${ }^{5}$

Other recent investigations deal with the effect of the anisotropy $^{21}$ and the relative contributions ${ }^{22}$ of the polarization rotation versus polarization extension on the piezoelectric properties.

Using the hypotheses briefly discussed earlier, we can speculate on a physical model to describe our results.

\section{A. Physical model}

It is widely accepted that $90^{\circ}$ domains are highly mobile in the donor doped (soft) PZT ceramics as a consequence of the increase of lead vacancies in the crystal lattice as charge compensation, ${ }^{23}$ as well as reducing the concentration of the oxygen vacancies, ${ }^{24}$ which are thought to clamp the domain wall motion. ${ }^{25}$ Based on this assumption, we may expect that $90^{\circ}$ domains can be switched relatively easily upon applying an electric field. In fact, theoretical calculations ${ }^{26}$ of $\mathrm{PbTiO}_{3}$ support the existence of a relatively low barrier of $90^{\circ}$ domain wall switching. However, a large internal stress is developed due to the dimensional deformation associated with $90^{\circ}$ domain. $^{18}$

It has been shown in this work that the double peak switching is only occurring once the forward single switching peak is developed, Fig. 6. The separation between the two reversed peaks is also function of the forward applied field, Fig. 7. The splitting is the same for a ramped field and a suddenly applied field. This confirms the relatively easy switching for the soft PZT, contrary to the behavior of the PZT-5. ${ }^{17}$

Based on the information mentioned earlier, we may consider the following model. In the virgin state, when all domains are randomly oriented, the poling electric field induces mainly $180^{\circ}$ and $90^{\circ}$ domains. Possibly, the $90^{\circ}$ domains can be switched relatively easily. However, a large inhomogeneous internal stress is developed due to the dimensional deformation caused by $90^{\circ}$ domain switching. ${ }^{18}$ Upon reversing the applied field in the opposite direction $(E$ to $-E$ ), the reverse peak is gradually splitting depending on how far the forward peak is developed. This splitting may indicate the amount of $90^{\circ}$ domain switching and consequently the amount of internal stress introduced. As the forward applied field increases, more $90^{\circ}$ domains switch introducing additional stresses. Upon a subsequent field reversal and due to the already developed stresses instead of direct $180^{\circ}$ switching, the switching occurs favorably via two successive $90^{\circ}$ domain rotations ${ }^{18,27,28}$ as the large residual stress and electric field can make $90^{\circ}$ domain switching energetically easier than direct $180^{\circ}$ domain switching. ${ }^{18}$ It is assumed in this explanation that the maximum polarization 
in both directions of the field is the same. It is worthwhile to mention that this behavior is occurring on subsequent field reversal as a result of the permanent residual stress, Fig. 5.

The reverse switching (both steps) is found to be slightly delayed with respect to the forward peak position due the fact that the threshold electric field needed for $90^{\circ}$ is always higher due to the low mobility of the $90^{\circ}$ domain walls, which must be reflected in the poling process as a function of time. ${ }^{4}$ It has been shown that the second step of $90^{\circ}$ domain switching should take place in a short interval of electric field, estimated ${ }^{18}$ as $0.4 \mathrm{kV} / \mathrm{cm}$. We found in our case that the observed two switching peaks on reverse poling are separated in $0.6 \mathrm{kV} / \mathrm{cm}$ in a good agreement with the results of Achuthan and Sun. ${ }^{18}$

Broadening of the pyropeak for the reversely poled sample, Fig. 4(b), enhances the idea of two successive thermal depolarization transitions for the $90^{\circ}$ domains. It is commonly believed that a negative electric field induces $180^{\circ}$ domain switching (e.g., Ref. 29). However, we have shown here that electrical behavior is consistent with the microstructural observations made by Liu et al. $^{3}$ indicating non$180^{\circ}$ or $90^{\circ}$ domain switching. This would also be an explanation for the same behavior observed by other authors. ${ }^{6,30} \mathrm{~A}$ study of the effect of the grain size on this $90^{\circ}$ domain switching as seen by our switching current experiment is currently under way.

\section{CONCLUSION}

Modified donor doped PZT shows a single polarization current peak during poling. During reverse poling a double peak in the switching current is observed. Similar behavior is also observed in the pyroelectric current curve. This double peak in the switching curve is attributed to the residual stresses developed during forward poling that transforms the switching mode from a single threshold coercive field to double threshold coercive field. It is concluded that the re- sidual stress makes switching via two successive rotations are energetically easier than direct $180^{\circ}$ domain switching.

${ }^{1}$ W. J. Merz, Phys. Rev. 95, 690 (1954).

${ }^{2}$ T. M. Kamel, F. X. N. M. Kools, and G. de With, J. Eur. Ceram. Soc. 27, 2471 (2007).

${ }^{3}$ M. Liu, K. J. Hsia, and M. R. Sardela, J. Am. Ceram. Soc. 88, 210 (2005).

${ }^{4}$ M. H. Lente and J. A. Eiras, J. Appl. Phys. 89, 5093 (2001).

${ }^{5}$ C.-T. Sun and A. Achuthan, J. Am. Ceram. Soc. 87, 395 (2004).

${ }^{6}$ U. Belegundu and K. Uchino, J. Electroceram. 6, 109 (2001).

${ }^{7}$ E. Fatuzzo and W. J. Merz, Phys. Rev. 116, 61 (1959).

${ }^{8}$ H. Fan and H. E. Kim, J. Appl. Phys. 91, 317 (2002).

${ }^{9}$ S. B. Lang, Source Book of Pyroelectricity (Gordon and Breach Science, London, 1974)

${ }^{10}$ G. Arlt, J. Mater. Sci. 25, 2655 (1990).

${ }^{11}$ C. F. Pulvari and W. Keubler, J. Appl. Phys. 29, 1315 (1958).

${ }^{12}$ A. Levstik, M. Kosec, V. Bobnar, C. Filipič, and J. Holc, Jpn. J. Appl. Phys., Part 1 36, 2744 (1997)

${ }^{13}$ K. Dimmler, M. Parris, D. Butler, S. Eaton, B. Pouligny, J. F. Scott, and Y. Ishibashi, J. Appl. Phys. 61, 5467 (1987).

${ }^{14}$ V. Shur, E. Rumyantsev, and S. Makarov, J. Appl. Phys. 84, 445 (1998).

${ }^{15}$ S. Ikeda, T. Fukada, and Y. Wada, J. Appl. Phys. 64, 2026 (1988).

${ }^{16}$ V. Shur, E. L. Rumyantsev, S. D. Makarov, A. L. Subbotin, and V. V. Volegov, Integr. Ferroelectr. 10, 223 (1995).

${ }^{17}$ F.-X. Li, D.-N. Fang, and A.-K. Soh, Smart Mater. Struct. 13, 668 (2004).

${ }^{18}$ A. Achuthan and C.-T. Sun, Proc. SPIE 5387, 379 (2004).

${ }^{19}$ H.-T. Chung, B.-C. Shin, and H.-G. Kim, J. Am. Ceram. Soc. 72, 327 (1989), and references therein.

${ }^{20}$ S. Li, A. S. Bhalla, R. E. Newnham, L. E. Cross, and C. Huang, J. Mater. Sci. 29, 1290 (1994).

${ }^{21}$ D. Damjanovic, J. Am. Ceram. Soc. 88, 2663 (2005).

${ }^{22}$ M. Davis, M. Budimir, D. Damjanovic, and N. Setter, J. Appl. Phys. 101, 054112 (2007)

${ }^{23}$ P. Gerthsen, K. H. Hardtl, and N. A. Schmidt, J. Appl. Phys. 51, 1131 (1980).

${ }^{24}$ T. Tsurumi, Y. Kumano, N. Ohashi, T. Takenaka, and O. Fukunaga, Jpn. J. Appl. Phys., Part 1 36, 5970 (1997).

${ }^{25}$ K. Carl and K. Hardtl, Ferroelectrics 17, 473 (1978).

${ }^{26}$ B. Meyer and D. Vanderbilt, Phys. Rev. B 65, 104111 (2002).

${ }^{27}$ N. Bar-Chaim, M. Brunstein, J. Grunberg, and A. Seidman, J. Appl. Phys. 45, 2398 (1974).

${ }^{28}$ S. Li, A. S. Bhalla, R. E. Newnham, L. E. Cross, and C. Huang, J. Mater. Sci. 29, 1290 (1994).

${ }^{29}$ E. Fatuzzo and W. J. Merz, Ferroelectricity (North-Holland, Amsterdam, 1967).

${ }^{30}$ V. Gopalan and T. E. Mitchell, J. Appl. Phys. 83, 941 (1998). 